\title{
Erratum
}

To the paper

\section{Particle-size dependent distribution of thorium and uranium isotopes in soil}

O. Frindik, S. Vollmer

Central Laboratory of Isotope Studies, Federal Research Centre for Nutrition, Haid- und Neu-Straße 9, D-76131 Karlsruhe, Germany (Received September 28, 1998)

appeared in the Journal of Radioanalytical and Nuclear Chemistry, Vol. 241, No. 2 (1999) 291-296.

On pages 293, 294 and 295, Figures 2, 3 and 4 are as follows:
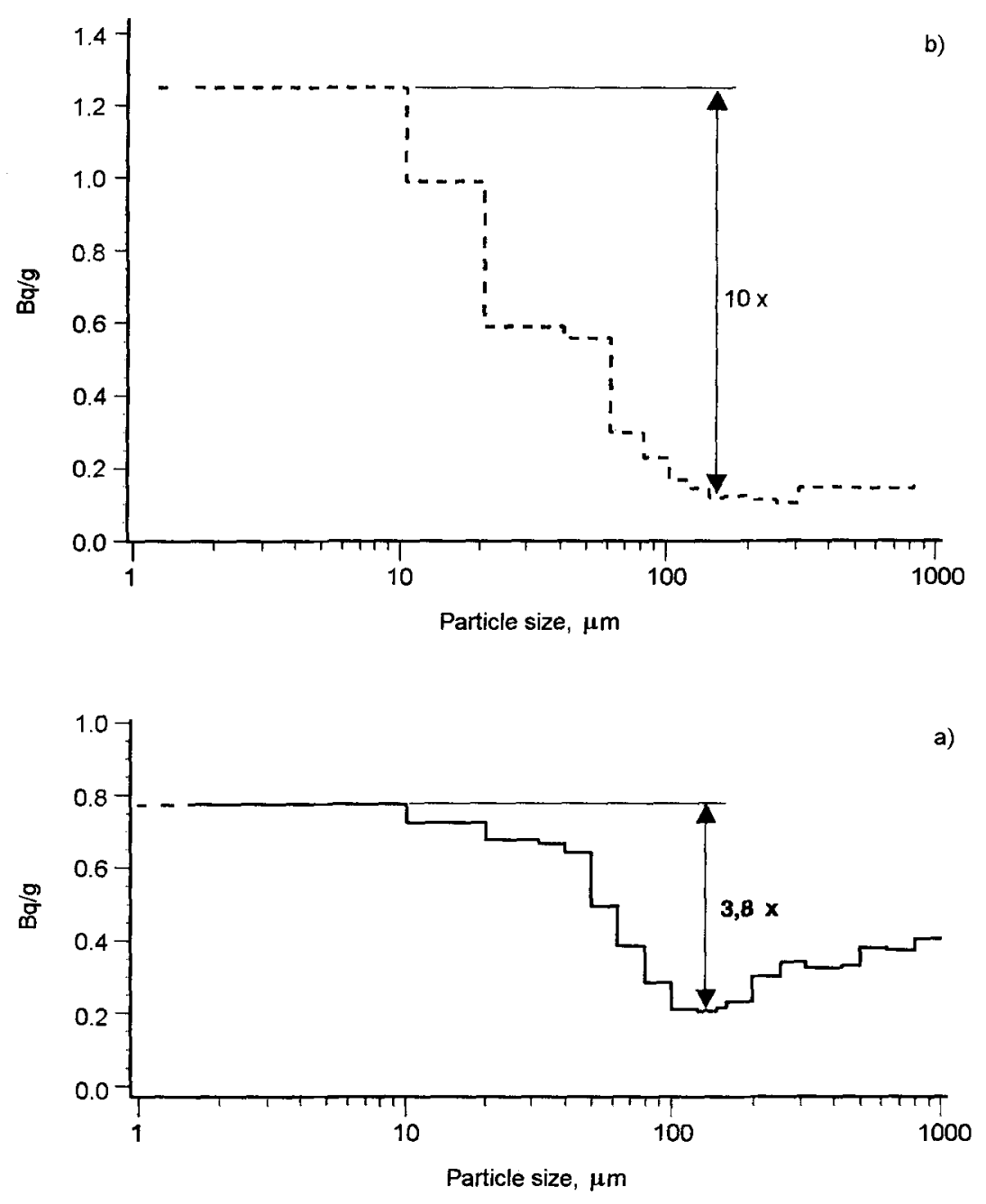

Fig. 2. Total alpha-activity of sieving fractions; wet sieving (b), dry sieving (a) 
ERRATUM

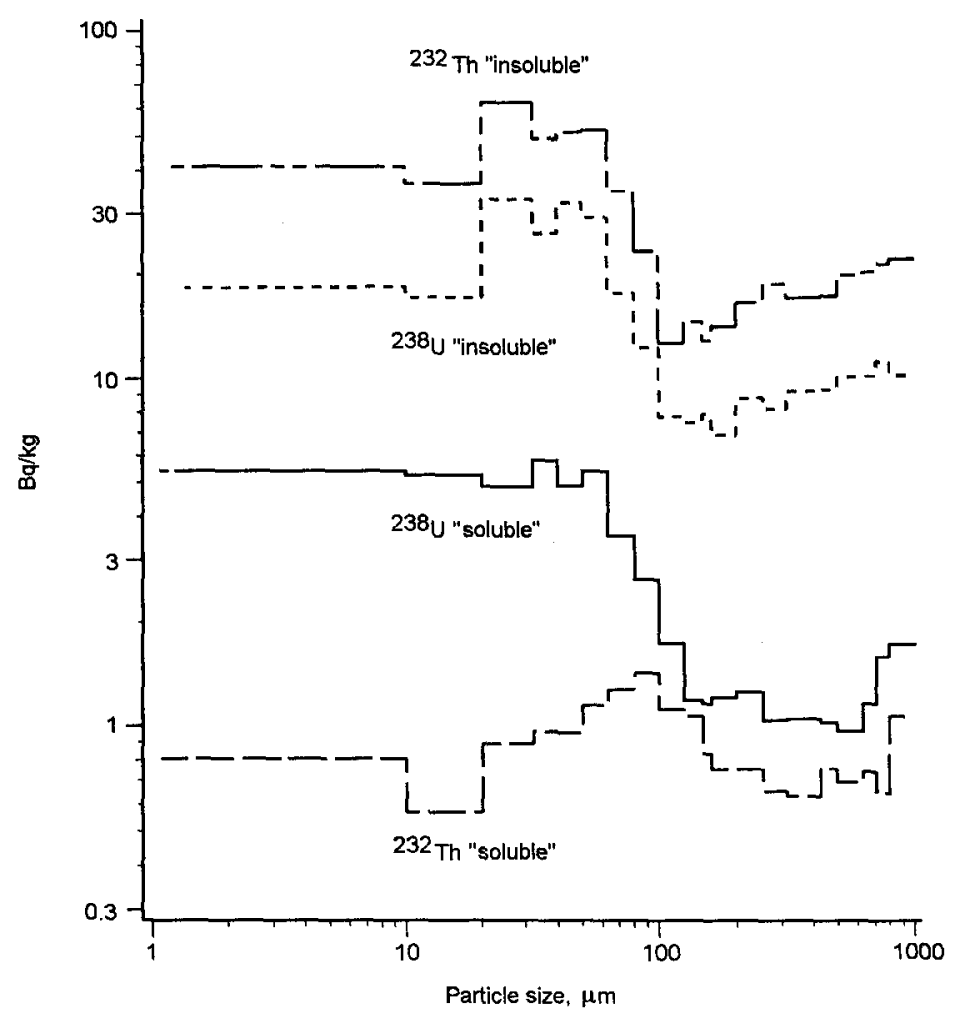

Fig. 3. Dry sieving; distribution of ${ }^{232} \mathrm{Th}$ and ${ }^{238} \mathrm{U}$ in soil

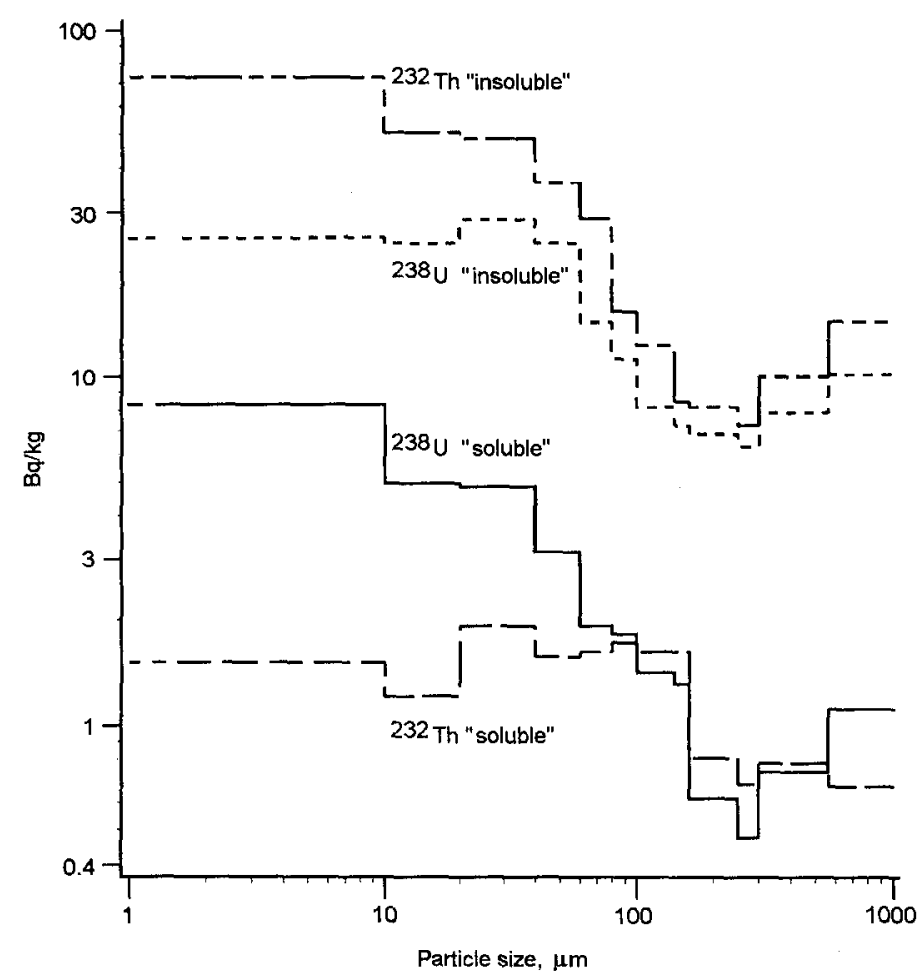

Fig. 4. Wet sieving; distribution of ${ }^{232} \mathrm{Th}$ and ${ }^{238} \mathrm{U}$ in soil 